\title{
EARTHQUAKE-INDUCED BUILDING DETECTION BASED ON OBJECT-LEVEL TEXTURE FEATURE CHANGE DETECTION OF MULTI-TEMPORAL SAR IMAGES
}

\author{
Detecção de construções induzidas por terremoto baseada na detecção de \\ modificações nos traços de textura em nivel de objeto de imagens SAR \\ multitemporais \\ Qiang Li ${ }^{1}$ - ORCID: 0000-0002-9559-2170 \\ Lixia Gong ${ }^{1}$ \\ Jingfa Zhang ${ }^{1}$ \\ ${ }^{1}$ Key Laboratory of Crustal Dynamics, Institute of Crustal Dynamics, \\ China Earthquake Administration, Beijing, China. \\ E-mail: liqiang08@hotmail.com; gonglixia08@163.com; zhangjingfa08@163.com
}

Received in April 17 2017

Accepted in June $29^{\text {th }} 2018$

\begin{abstract}
:
The damage of buildings is the major cause of casualties of from earthquakes. The traditional pixel-based earthquake damaged building detection method is prone to be affected by speckle noise. In this paper, an object-based change detection method is presented for the detection of earthquake damage using the synthetic aperture radar (SAR) data. The method is based on object-level texture features of SAR data. Firstly, the principal component analysis is used to transform the optimal texture features into a suitable feature space for extracting the key change. And then, the feature space is clustered by the watershed segmentation algorithm, which introduces the concept of object orientation and carries out the calculation of the difference map at the object level. Having training samples, the classification threshold values for different grade of earthquake damage can be trained, and the detection of damaged building is achieved. The proposed method could visualize the earthquake damage efficiently using the Advanced Land Observing Satellite-1 (ALOS-1) images. Its performance is evaluated in the town of jiegu, which was hit severely by the Yushu Earthquake. The cross-validation results shows that the overall accuracy is significantly higher than TDCD and IDCD.
\end{abstract}

Keywords: Earthquake Damage Detection; Segment; Synthetic Aperture Radar; PCA; Damage Assessment 


\section{Resumo:}

Danos a edifícios são a principal causa de mortalidade nos terremotos. O método tradicional de detecção de construções danificadas por terremotos baseado em pixels pode ser afetado pelo ruído speckle. Neste artigo, apresenta-se um método de detecção de mudanças baseado em objetos para a deteç̧ão dos dano de terremotos usando dados de radar de abertura sintética (SAR). O método baseia-se em feições de textura em nível de objeto dos dados SAR. Em primeiro lugar, a análise da componente principal é usada para transformar as feições de textura ótimos em feições espaciais adequadas para extrair a mudança central. Posteriormente, as feições espaciais são agrupadas pelo algoritmo Watershed de segmentação, o qual introduz o conceito de orientação do objeto e desenvolve o cálculo do mapa de diferenças no nível do objeto. Tendo amostras de treinamento, é possível treinar os valores de limiar de classificação para diferentes graus de danos por terremoto, e consegue-se realizar a detecção dos edifícios danificados. 0 método proposto pode visualizar os danos por terremoto de forma eficiente usando imagens do satélite ALOS-1 (Advanced Land Observing Satellite-1). Seu desempenho foi avaliado na cidade de Jiegu, gravemente afetada pelo terremoto Yushu. Os resultados de validação cruzada mostram que a precisão geral é significativamente maior do que aquelas do TDCD e IDCD.

Keywords: Detecção de danos por terremoto; segmento; radar de abertura sintética; PCA; avaliação de danos.

\section{Introduction}

A rapid earthquake damage detection right after a seismic event can address first aid and relief towards the most affected areas. Thus, the most precise estimation, the better decisions can be made during emergency disaster. Satellite data has shown excellent capability for use in rapid impact assessments, as it can provide information for damage mapping in large areas and in an uncensored manner, particularly when information networks are inoperative and road connections are destroyed in areas impacted by earthquakes. The damage detection based on change detection techniques is capable of observing an object at different times and of identifying changes. Change detection (CD) using satellite remote-sensing observations has been an important technique for various applications such as land-cover/land-use change analyses (Nunes and Auge 1999; Shalaby and Tateishi 2007), assessment of deforestation (Hosonuma et al. 2012; Römer et al. 2012), damage assessment (Domenikiotis, Loukas and Dalezios 2003; Kamthonkiat et al. 2011; Feng et al. 2014), disaster monitoring (Lahousse, Chang and Lin 2011; Kaiser et al. 2013), and other environmental changes.

Both optical and radar sensors can be exploited for change detection purposes. Compared with optical sensors, Synthetic aperture radar (SAR) is not affected by weather and lighting conditions that typically affect the observations in the optical spectral range, which has been widely used in building change detection to measure the extension of damage (XIONG et al. 2012; AGHABABAEE et al. 2013; HANCHICHAS et al. 2014; MARINO et al. 2014).Building damage assessment is usually regarded as a change detection problem (Gamba et al. 2007; Jin et al. 2009; Balz et al. 2010), in which the mapping classes are correlated with the grade of damage suffered by the buildings. 
In the published literature, three approaches have usually been explored. The first approach involves investigating the amount of decorrelation due to the change in the orientation of a strong scatter, causing a sudden decrease in the usually high temporal interferometric coherence in urban areas. The second approach explores for intensity (or amplitude) changes using differences in backscattering behavior due to geometric changes in the wave-target interactions. The third approach involves combining interferometric decorrelation and intensity changes for damage detection. Aoki, Matsuoka and Yamazaki (1998) used backscattering differences and intensity correlation coefficients to quantitatively evaluate building damage using ERS-1 images for the 1995 Hyogoken-Nanbu earthquake. In subsequent research, the interferometric coherence is adopted to analyze the damage (Yonezawa and Takeuchi 1999). Yonezawa et al. (1999; 2001; 2002) applied ERS-1 interferometric coherence to detect the damaged buildings related to the 1995 Hyogoken-nanbu earthquake in Japan. They found the collapse and damaged buildings caused decorrelation between the data acquired before and after the earthquake. Matsuoka and Yamazaki (2000) also used ERS-1 coherence to investigate the 1999 Kocaeli earthquake in Turkey. In addition to the interferometric coherence, a derived coefficient called the temporal coherence ratio was adopted to quantitatively analyze the damage (Ito, Hosokawa and Matsuoka 2002; 2003). SAR intensity information seems to be more commonly applied in damage assessment (Matsuoka et al. 2004a, 2004b, 2005, 2007, 2010a, 2010b; Yamazaki, Inoue and Liu 2010). Gong, Yang and Zhang (2017) applied deep neutral networks to SAR images change detection without the generation of difference image, in which change detection problem is transformed into a classical classification task. Hou et al. (2017) present a novel unsupervised change detection method in SAR images based on image fusion strategy and compressed projection. Moya et al. (2017) estimated the distribution of building damage by joining these two sources of information: change detection of pre-and post-event SAR images and spatial distribution of strong motion intensity. Sharma et al. (2017) presents Earthquake Damage Visualization (EDV) based on the pre-seismic and co-seismic coherence change method.

Unfortunately, the strong intensity variations problem is exacerbated by speckle noise. Moreover, the existing methods are usually based on the pattern of pixel analysis, resulting in low accuracy of information detection. These have led to the generation of segmentation techniques and object-based analysis methods. Object-based methods, emphasizing, first, in creating the image objects and then using them for further analysis (Chen et al. 2012). The object-based image analysis (OBIA) are applied considered for $C D$, namely, object-based change detection (OBCD) techniques (Blaschke, Lang and Hay 2008; Blaschke 2010). The OBCD uses image objects for analyzing change information by comparing segmentation and classification results. Otherwise, it can extract change information by comprehensively analyzing the objects of multi-temporal images using spectral, texture and structure information. Consequently, this method has normally high detection accuracy and robustness (Chen et al. 2012; Hussain et al. 2013). Recently, most of OBCD algorithms have been developed for various applications, including vegetation change (Wulder et al. 2008), urban change (Bouziani, Goïta and He 2010), and other applications. Walter (2004) introduced object-based classification and compared it to pixel-based classification. His results stated that the object-based classification was good for inhomogeneous areas. Recent studies have assessed the use of OBCD algorithms in order to interpret various types of urban damage caused by natural disasters such as earthquakes or tsunamis (Tanathong, Rudahl and Goldin 2009). Chen et al. (2012) presented the potential of using high spatial resolution remotely sensed imagery in $C D$ and motivated the use of $O B C D$ in 
comparison to pixel-based change detection (PBCD). He showed that OBCD improved the ability to identify the changes for geographic entities found over a given landscape.

Most existing earthquake damage change detection methods based on SAR images mainly used gray information (Huang et al. 2010; Gao, Zhang and Wang 2010; Hao, Zhang and Shi 2012; AGHABABAEE, TZENG and AMINI 2012; Hu 2013). Due to the existence of obvious speckle noise in SAR images (Han, Guo and Wang 2002), detection results usually had high false alarm rates and false negative rates, in which case we can reduce the effects of speckle noise using image processing methods (Serpico and Moser 2007). With improvements in the resolution of SAR images, texture features were used as the type of image information that can reduce the influence of speckle noise (Wang et al. 2011; Gong et al. 2014). SAR images contain rich texture features, and scholars in China and abroad have used texture for SAR image information extraction (Liu and Guo 1995; HEROLD, AACK and SOLOMON 2004; WAL, HERMAN and Dool 2005; YAKOUB, LORENZO and FARID 2005; Berberoglu et al. 2007). Wu, Wang and Zhang (2005) fused gray level co-occurrence matrices to calculate texture features of high-resolution SAR images, and then applied an unsupervised classification analysis to extract residences through a statistical analysis of selected suitable feature vectors. Zhao, Qin and Gao (2008) proposed a construction area extraction method based on a gray level co-occurrence texture analysis. This method can extract construction areas effectively and is based on the Bhattacharyya distance and the K-Nearest Neighbor (KNN) classification process. Numerous studies have indicated that gray level information from texture-aided images can improve the accuracy of information extraction from the images (Xie, Zhang and Xu 2007; Zhang, She and Pan 2008; Zhao, Zhang and Li 2008).

Currently, research on change detection using texture information is usually based on a single texture or a few texture features that are suitable for the given area. The conventional methods of change detection based on texture features are usually expressed in terms of a difference map. These methods use pixel-based calculations and cannot represent the whole changes in the depicted image. Besides, this type of methods are very sensitive to the differences in radiation with different epochs, especially the noise in SAR images. Furthermore, the PBCD methods remove the links between nearby pixels and abandon the integrity of the imaging target.

To solve these problems, in this article, an object-level CD method based on the principal component analysis (PCA) of text features of pre- and post-event SAR imagery is proposed. This study focuses on object-based comparison and change image generation using multi-temporal SAR images. The principal component of multi texture features is used to replace the traditional intensity features and constructed change image to realize the detection of earthquake damaged buildings. This could help improve the quality of the change image and, consequently, the overall change detection accuracy.

The remainder of this paper is organized as follows: Section 2 describes the new method for change detection with texture features segmented using the watershed segmentation algorithm. Section 3 introduces the datasets used in this article. Section 4 presents the experimental results. Finally, the discussion and the conclusions are presented in Section 5 and Section 6 respectively. 


\section{Methodology}

The proposed method consists of the following five main processes: (1) Image pre-processing and urban area mask; (2) Texture features generation; (3) Dimensionality reduction; (4) PC objects generation using the watershed segmentation algorithm; and (5) automatic classification of objects based on CD. The technical flowchart used in the method is shown in Figure 1. Prior to the feature generation, images from two different times need to be co-registered to show the same geographical area. The registration method based on scale-invariant feature transform (SIFT) is adopted in this study. To exclude the influence of non-urban area, the existing urban vector data are used to mask the image and extract the urban area. The vector data can be obtained by visual interpretation of high-resolution optical images.

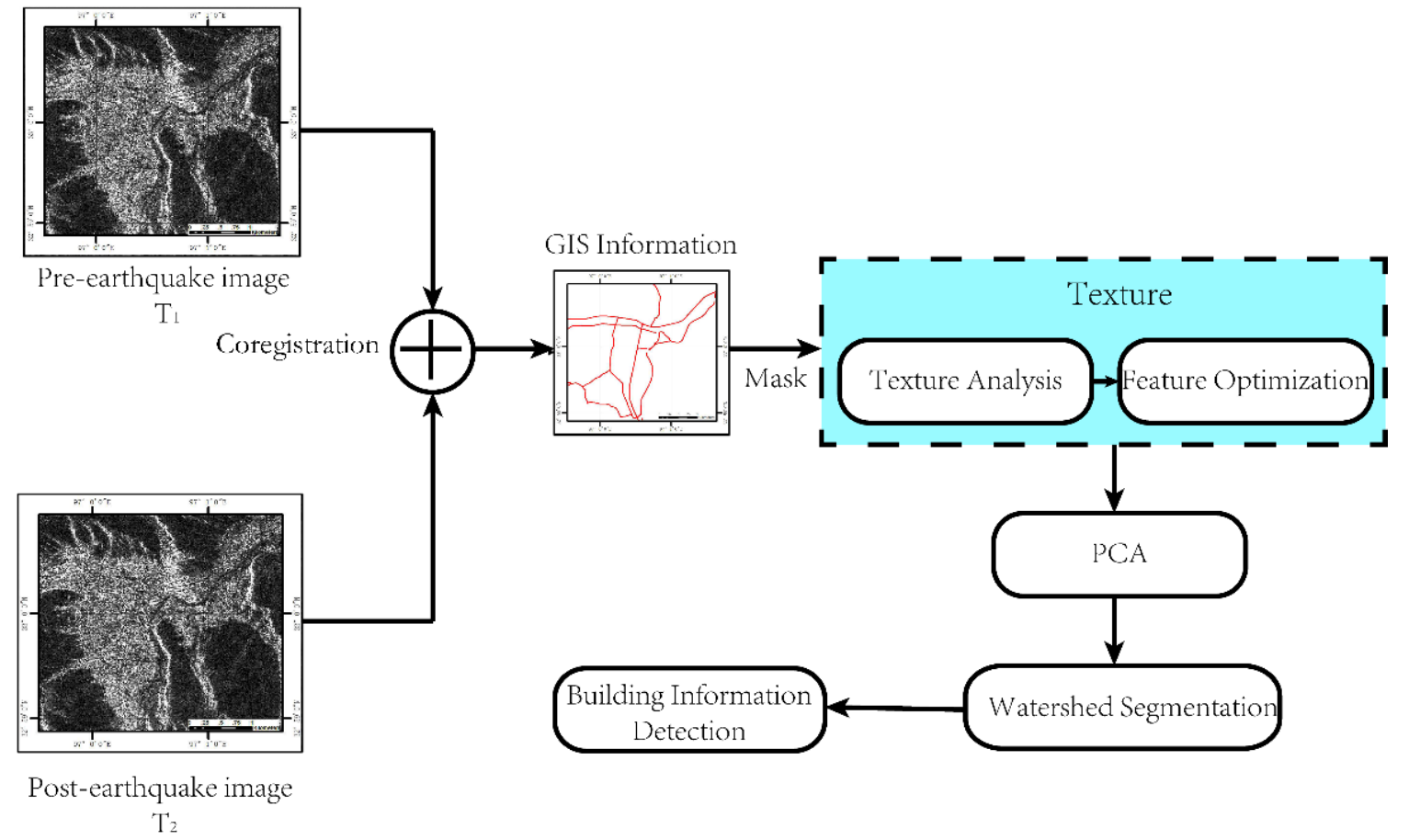

Figure 1: Flowchart of the proposed approach

\subsection{Concept of Seismic classification}

Ground investigation of building damage is conducted based on the classification in the Chinese Seismic Intensity Scale GB/ T17742-2008 (China earthquake Administration, 2008), buildings are classified into 5 categories in China which include (1) slight damage, (2) moderate damage, (3) substantial to heavy damage, (4) very heavy damage and (5) destruction. The evidence of the damage degree of buildings provided by remote sensing data is different from that of field surveys. Interpretation of earthquake damaged buildings is mainly based on the damage reflected at the tops of the buildings in remote sensing images.

In consideration of SAR images can provide some information about the sides of buildings, because of the influence of the imaging mode and the spatial resolution, SAR images cannot detect details of walls, interiors or foundations of buildings. However, a macro-scale ground 
investigation can provide a more comprehensive investigation of building structure type, bearing components, cracks, etc. Taking into account the above considerations, remote sensing seismic damage investigation is usually divided into 3 categories, (1) intact building, (2) moderately damaged building (containing the second and third category in ground investigation), and (3) destroyed building (containing the fourth and fifth category in ground investigation), through the combination with ground investigation results.

\subsection{Texture features generation}

Textures represent the characteristics of the object surface. They are important indicators of the discrimination of surface features. As the texture of SAR image is rich, texture analysis of SAR images has been extensively used in various fields. Due to the lack of spatial information in SAR images, abundant texture information becomes the best choice for information detection.

The statistical analysis method is an effective method for texture analysis. It is mainly used to describe the random and spatial statistical characteristics of the texture primitives or local patterns to show the consistency and the differences of the regions. Texture feature analysis based on gray level co-occurrence matrices (GLCM) is a classic statistical analysis method that has been applied to the texture extraction from high-resolution remote sensing images and multi-spectral remote sensing images (Hu, Li and Du 2009). GLCM emphasizes the spatial dependence of the gray level, which is characterized by the spatial relationship among the pixels in a texture pattern (Chen and Deng 2002).

The co-occurrence probability feature method (CPFM) is adopted to extract texture features in this study. CPFM is a statistical method based on texture description, which uses the GLCM to describe the texture features (TUCER, YAN and JAIN 1998). Haralick, Shanmugan and Dinstein (1973) proposed 14 features base on GLCM for textural analysis. These features measure different aspects of the GLCM, and some features are correlated. In this study, eight texture features are chosen for analysis: the mean (ME), variance (VA), contrast (CON), entropy (ENT), homogeneity (HOM), dissimilarity (DI), correlation (COR), and angular second moment (ASM).

\subsubsection{Parameters of GLCM-based Textural Features}

Generally, if the textural measures derived from the GLCM are used, some fundamental parameters should be defined, including the quantization level of the image, window size, step size and the orientation values of the measurements. The orientation parameter is less important compared to other factors in the co-occurrence matrix. The arrangement direction of the buildings in the earthquake zone is complex and diverse, therefore, in the experiments, the average value of four orientation of $0^{\circ}, 45^{\circ}, 90^{\circ}$ and $135^{\circ}$ is taken as the GLCM of the local image center pixel position. The image quantization is a fundamental parameter, a level of 64 is adopted in the study. A smaller step size can reflect the texture characteristics. In the article, we chose 1 as the step length to calculate the texture features.

To calculate texture features for each pixel in an image, a moving window is usually used to define the neighborhood of a pixel and the texture measurement calculated from the window is assigned to the center pixel. The window size for texture analysis is usually related to image 
resolution and the contents within the image. A large texture computation window produces relatively stable texture measurements but creates large edge effects; if a small texture computation window is used, the edge effect is small, but it is generally difficult to produce stable texture measurements. Texture classification experiments with simulated data show that texture separability increases with increases in the calculation of the texture window, but the evaluation of pixel edges outside the separability may be overestimated (Ferro 2002). The discrimination of building image texture features in different earthquake damage levels is usually applied for estimating window size. If the discrimination can reach the highest, then the window size will be chosen as the optimal size.

Based on the field investigation data, 3 blocks with different damage degree are chosen as samples from the Advanced Land Observing Satellite-1 (ALOS-1) data of Yushu earthquake by building mask. The number of pixels contained in the samples is 85, 66, and 109 respectively. Taking VA and ENT as examples, the changes of feature value are compared with different window size from $3 \times 3$ to $51 \times 51$ at intervals of 4 , as shown in Figure 2 . As the computation window becomes larger, the texture characteristic value becomes larger and then smaller after reaching a peak value. When the window size is 11 , the characteristic value of the damaged buildings at different levels reaches its maximum, and the VA is better. In terms of the ENT change, the discrimination between intact building and moderately damaged building is not obvious, but the identification of damaged building is better, which is conducive to extracting the information on damaged buildings. The results show that when the window size is 11 , the texture feature parameters of the calculation window are the strongest for the characterization of buildings with different damage grade. Based on the quantitative analysis, the $11 \times 11$ pixels window size is chosen to calculate the GLCM in the experiments.
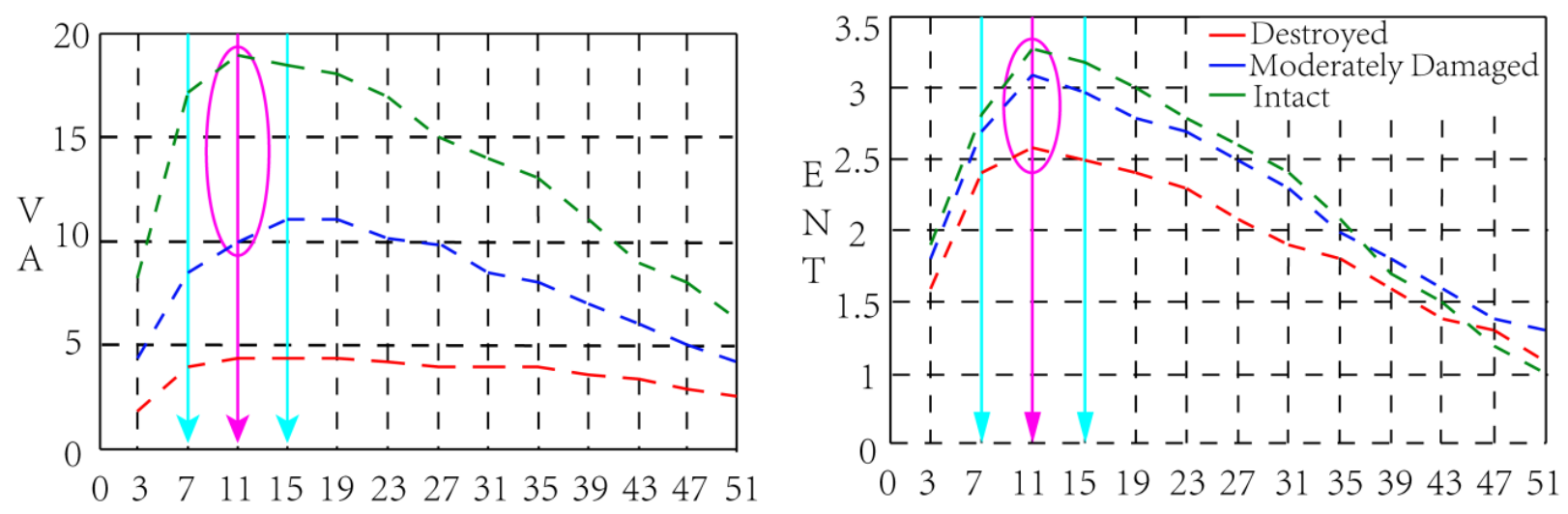

Figure 2: Curves showing the texture feature parameters with the change in window size

\subsubsection{Texture Feature Selection}

All the texture features can express the earthquake damaged buildings; however, redundant feature redundancy is easy to be caused by multiple texture features. In our experiment, the obvious and clear buildings are chosen as samples to carry out the comparison analysis to determine the optimal texture features. Because of texture feature of moderately damaged building is located between that of intact building and the destroyed building, therefore, we only choose intact building and destroyed building for texture feature comparison analysis. The 
number of intact building and destroyed building is 25 and 39 respectively. The texture feature parameters are as follows: ME, VA, CON, ENT, HOM, DI, COR, and ASM.

To illustrate the dissimilarity between the different features, the actual feature parameters are enlarged 10 times. Figure 3 shows the statistical analysis of the range of the characteristic values. As shown in the figure, there are differences in the ability to distinguish different grade of earthquake damaged buildings. The parameter value of the ME, VA and HOM are smaller in the overlap distribution between the intact building and the damaged building. The results indicate that the three features can be used to distinguish buildings with different grades. Consequently, $\mathrm{ME}, \mathrm{VA}$ and $\mathrm{HOM}$ are chosen to detect the information in this experiment.

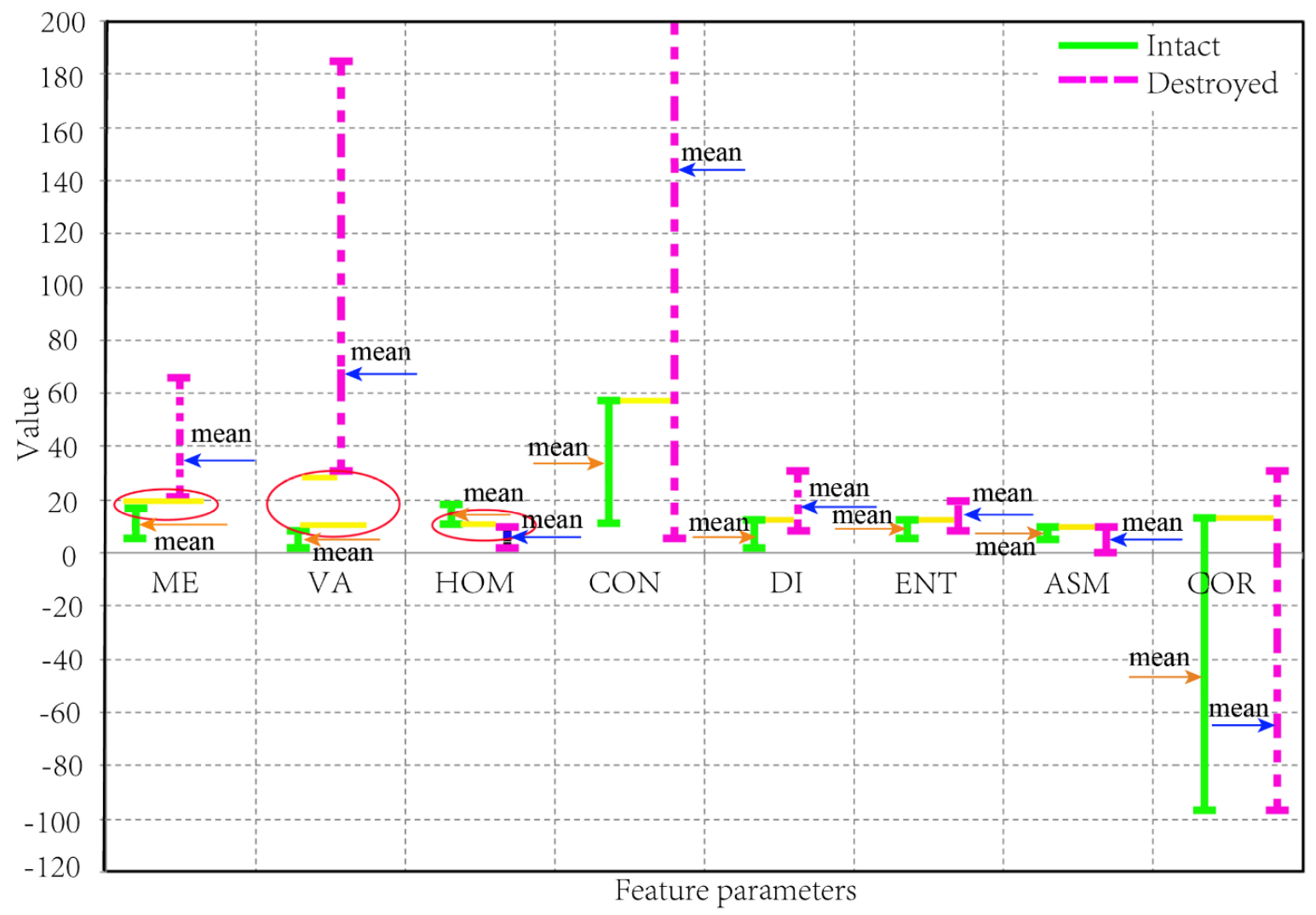

Figure 3: Statistical distribution of the SAR image feature parameters of different types of buildings. The brown arrow represents the mean value of the intact buildings, and the blue arrow represents the mean value of the destroyed buildings. The yellow line indicate the difference in the texture features of buildings with different damage grades.

\subsection{Dimensionality reduction}

Different features of the data contain significant correlations, the dataset might have few samples and many features (i.e., the dataset consists of a small number of samples in high dimensional space). Such problems can lead to an increase in the complexity of the learning algorithm and a reduction of the generalization ability. PCA is a simple nonparametric method that can solve these problems, which is why it has been adopted widely in the fields of machine learning and pattern recognition (Jolliffe 1986; Abdi and Williams 2010). The central idea of PCA is to reduce the dimensions of the dataset as much as possible while preserving its variance. The 
combination of multiple texture features will have redundant information in the characterization of the seismic damage of buildings, which will affect the effectiveness of the method to a certain extent. The method of PCA will be used to eliminate the influence of redundant information and reduce the feature dimension.

PCA is performed on the three texture features obtained and set to generate three components. Table 1 illustrates the statistics information of each PC. The first PC contains $96.49 \%$ of the feature information, accordingly, the first PC is chosen to participate in the analysis. The analysis of the first PC can be found, the four characteristic parameters of HOM, CON, DI and ME constitute most of the information of the first PC, accounting for $29.7 \%, 23.4 \%, 15.6 \%, 10.1 \%$ respectively. The rest of the texture are VA, ENT, ASM, COR, which account for a small proportion.

Table 1: Statistics of each band information after principal component transformation

\begin{tabular}{l|c|c|c}
\hline PC & Characteristic Value & Standard Deviation & Proportion ( \% ) \\
\hline 1 & 4937.37 & 73.29 & 96.49 \\
\hline 2 & 127.22 & 15.24 & 3.36 \\
\hline 3 & 8.91 & 3.58 & 0.15 \\
\hline
\end{tabular}

\subsection{Unsupervised generation of texture feature segments}

Object construction refers to segmenting an image into several mutually disjoint segments whose internal features are relatively homogeneous and differ from each other. The spatial distribution of the buildings after earthquake is diverse and the structure is complex. To keep the consistency of segments and avoid the effects of PCs of multi texture features obtained by statistical methods, multi-data segmentation strategy is adopted in this study. The gradient images of Pcs of texture features in the multi-temporal data set are segmented using the same segmentation method. The segmentation is carried out using the watershed segmentation algorithm. This algorithm based on mathematical morphology belongs to the class of region growing segmentation methods, which is an iterative process. The algorithm is mainly divided into two steps. The first step is a sorting process, and the second step is the submergence process. In the algorithm, the feature level of each pixel is sorted from low to high, and then, each local minimum is judged and labeled by the first in first out (FIFO) structure within the threshold influence domain. Vincent and Soille (1991) were the first to apply this method to image segmentation. Watershed segmentation is a highly regarded and widely used segmentation technology (Gonzalez and Woods 2005). Watershed segmentation algorithm regards the image as a "topographic map", where the pixels with greater brightness values are larger, while the pixels in the darker areas are smaller. The image is segmented by seeking the "basin" and "watershed boundaries". In SAR images, intact buildings are expressed as a regular brightness area, while seismically damaged buildings appear as broken spots. These spots are favorable to the formation of catchment basins, which form in the surrounding watershed, and the formation of bright regional images, namely, image objects. Image segmentation is realized by marking different regions as injection points. In this experiment, three kinds of markers, such as intact buildings, moderately damaged buildings and destroyed buildings are marked. To eliminate the over segmentation caused by the small change of features in the image, we need 
to set the minimum suppression threshold to limit the gradient image, which is the most important setting parameter in the watershed segmentation algorithm. A schematic diagram showing watersheds and water basins is shown in Figure 4. More details about the segmentation algorithm can be found in Vincent and Soille (1991).

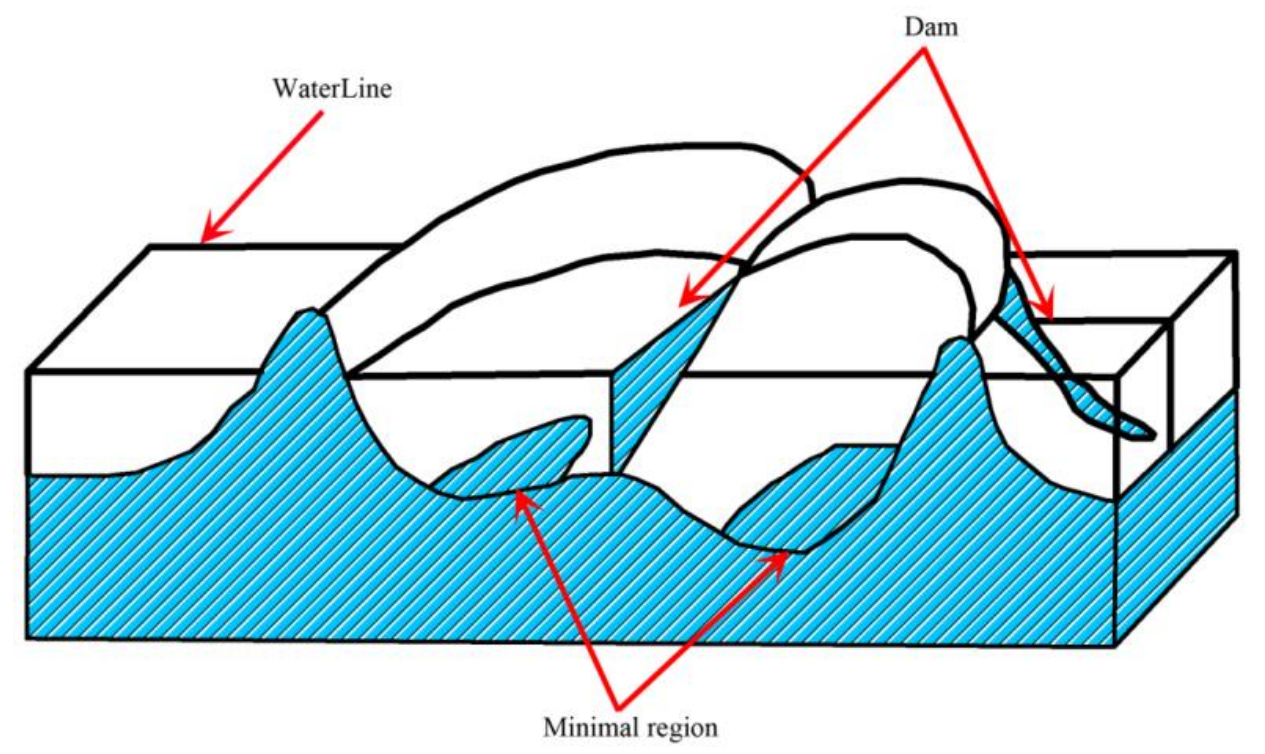

Figure 4: Schematic diagram of the watershed algorithm

\subsection{Change image generation and classification}

In this experiment, the different CD based on object is used to detect the change information. The difference CD method is the most commonly used image change detection method (Nualchawee and Tom 1978; Coppin and Bauer 1994; Miller, Fan, Ma and Li 2001). This method is used to process the original image data directly, and the algorithm is simple. Therefore, it can maintain the real information of the image and reflects the details of the image more accurately. Especially for medium-resolution images, the method has extensive application value and development potential. The basic principle of image difference change detection is shown in Equation (1).

$$
I_{D}(\text { Segment })=\mid I_{2}(\text { Segment })-I_{1}(\text { Segment }) \mid
$$

Where $I 1$ and 12 represent two images of the same region as epochs T1 and T2. ID(Segment) is the segment value of the difference image. If the segment does not change, the corresponding segment value in the difference image is close to 0 . If the segment value ID in the difference image is greater than the threshold value ID, it is believed that the segment has changed.

In this study, we select building samples with different category of damage in QuickBird images randomly to determine the reasonable threshold value. The number of intact building, moderately damaged building and destroyed building samples is 32,30 and 32 respectively. The mean value of the segment in which the sample pixel falls is calculated as the classification threshold. The distribution of sample points is shown in Figure 5. 


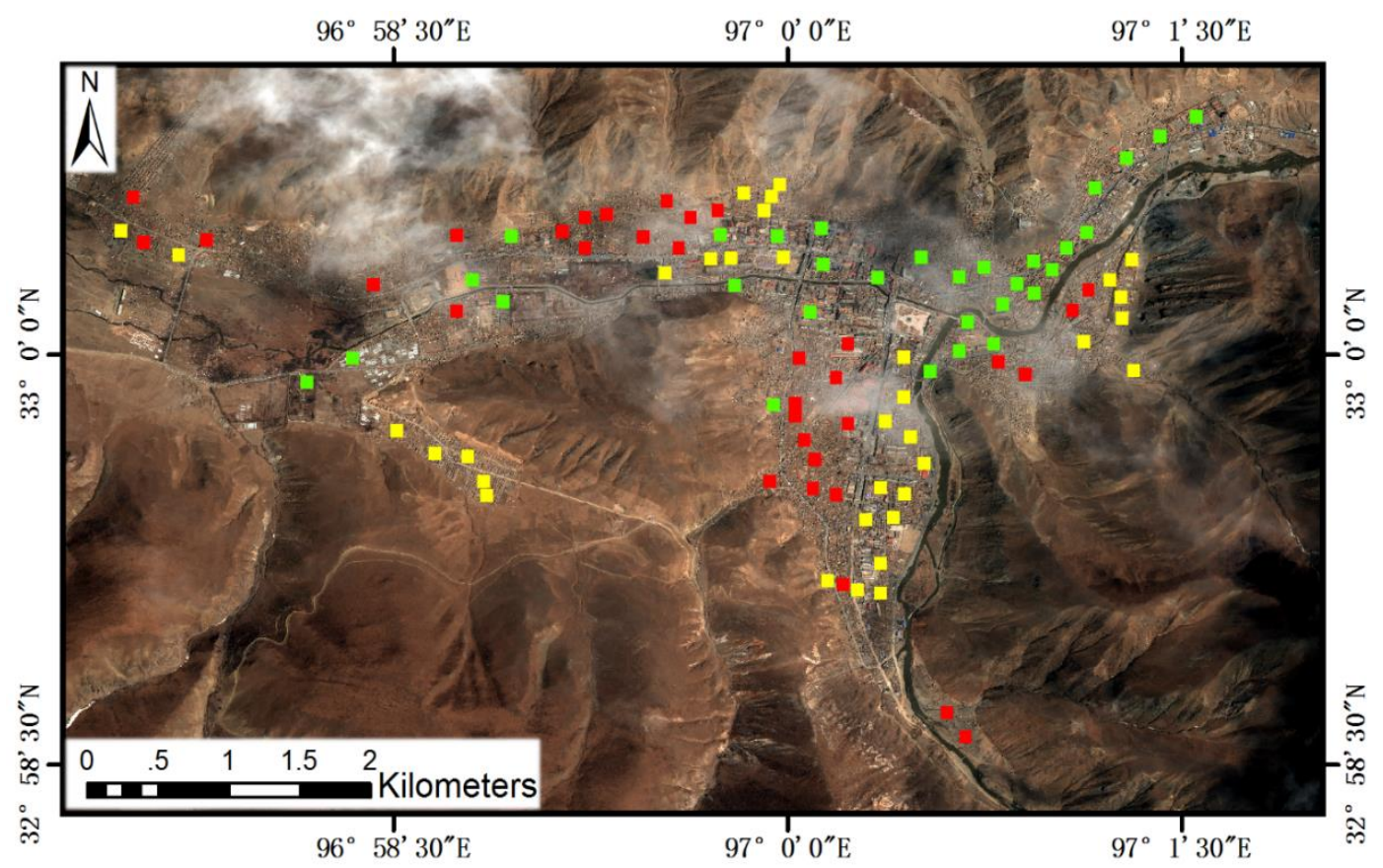

Figure 5: Sample distribution of building footprints with different damage categories (The green squares represent intact buildings; the yellow squares represent moderately damaged buildings; the red squares represent destroyed buildings).The base map is QuickBird image.

\section{Case Study}

The investigated case study is the Yushu earthquake on April 14, 2010 (Mw 7.1).The earthquake devastated a huge area in Qinghai province, killing and injuring a large number of people and causing major damage to buildings and other infrastructures (Yu 2010; Li et al. 2013). The earthquake epicenter was located near the town of Jiegu, Yushu County. Jiegu (centered at approximately $33.003^{\circ} \mathrm{N}$ and $97.006^{\circ} \mathrm{E}$ ) was one of the most affected areas.

Two ALOS-1 PALSAR intensity images on 2010.01.15 and 2010.04.17 with the direction of ascending were used for analysis and experimentation. The detailed parameter information of the dataset is shown in Table 2. An optical multispectral image covering the study area was used as reference data. On April 15, QuickBird satellite obtained a number of images of the areas including the town of Jiegu. After data fusion processing, the image is composed of 4 bands and the resolution is $0.6 \mathrm{~m}$. Based on the post-earthquake optical image, a reference map of the different grade damage buildings can be generated by careful interpretation. The reference map can be regarded as the ground truth for analysis and validation. Figure 6 illustrates the research area, the optical image and building distribution map. Figure 7 presents the experimental data, Figure 7(a) and Figure 7(b) illustrate ascending SAR images superimposed by the building distribution. The building distribution were generated by visual interpretation from optical image. 
Table2: SAR images used in this study

\begin{tabular}{|c|c|c|c|c|c|c|c|c|c|}
\hline $\begin{array}{l}\text { Acquisition } \\
\text { time }\end{array}$ & Satellite & $\begin{array}{l}\text { Wavelength } \\
(\mathrm{cm})\end{array}$ & Product & Type & $\begin{array}{c}\text { Polarization } \\
\text { mode }\end{array}$ & $\begin{array}{c}\text { Number of } \\
\text { Looks } \\
\text { (Azimuth/ } \\
\text { Range) }\end{array}$ & $\begin{array}{c}\text { Angle of } \\
\text { incidence } \\
\left({ }^{\circ}\right)\end{array}$ & Direction & $\begin{array}{l}\text { Spatial } \\
\text { resolution } \\
\text { (m) }\end{array}$ \\
\hline 2010/01/15 & $\begin{array}{l}\text { ALOS 1- } \\
\text { PALSAR }\end{array}$ & 23.6 & L1.5 & Intensity & $\mathrm{HH}$ & $4 / 2$ & 34.3 & ascending & 16 \\
\hline 2010/04/17 & $\begin{array}{l}\text { ALOS 1- } \\
\text { PALSAR }\end{array}$ & 23.6 & L1.5 & Intensity & $\mathrm{HH}$ & $4 / 2$ & 34.3 & ascending & 16 \\
\hline
\end{tabular}

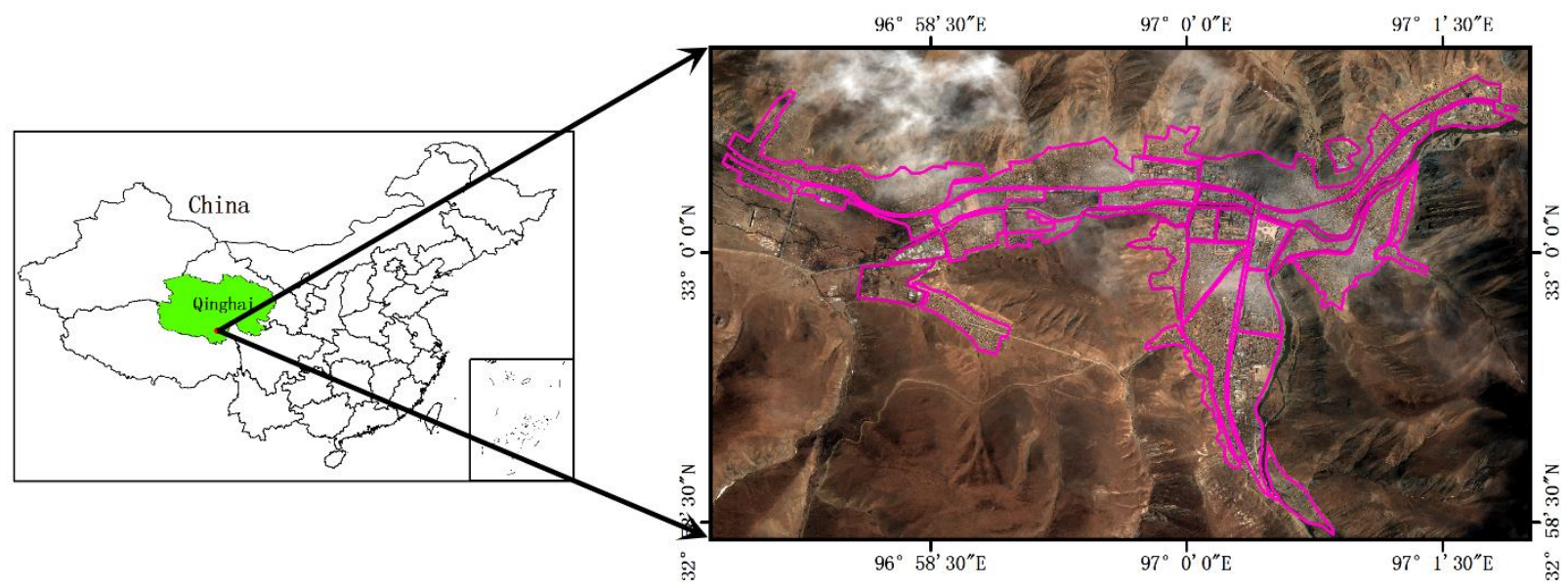

Figure 6: The specific scope and location of research area in Qinghai province (Red wire frame indicates building distribution). The optical image is QuickBird image. The image is composed of three bands of red, green, and blue.

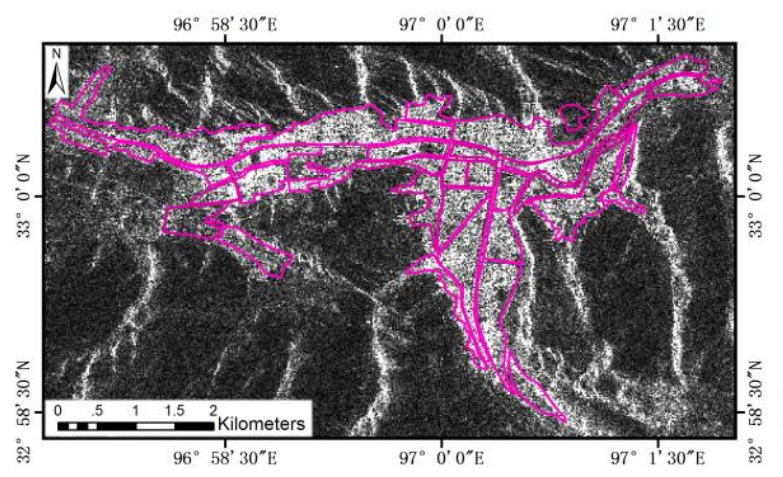

( a )

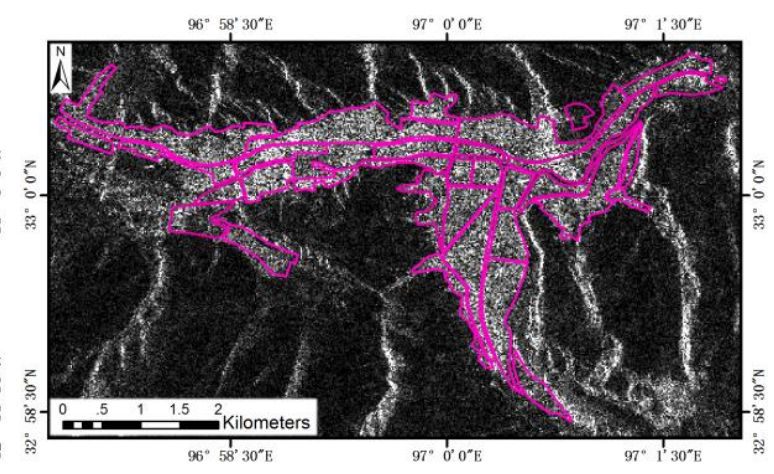

( b )

Figure 7: Multi-temporal SAR images of the Yushu earthquake zone ((a) The pre-earthquake ascending SAR image (the azimuth direction of the SAR image is from bottom to top, and the range direction is from left to right); (b) The post-earthquake ascending SAR image (the azimuth direction of the SAR image is from bottom to top, and the range direction is from left to right)).

The SAR images have been stretched to be illustrated more clearly. 


\section{Results and analysis}

Before analysis, the digital numbers of the multi-temporal ALOS-1 PALSAR data were converted into radar sigma naught values as follows:

$$
\sigma^{0}=\left(k_{s} \cdot|D N|^{2}-N E B N\right) \cdot \sin \theta_{l o c}
$$

where $k_{s}$ is the calibration and processor scaling given by the parameter calfactor in the annotated file, DN is the pixel intensity, and NEBN is the Noise Equivalent Beta Naught. It represents the influences of different noise contributions on the signal. $\theta_{l o c}$ is the local incidence angle. To maintain consistency of texture features, none of the images has been filtered. The segmentation was then carried out using the eCognition watershed segmentation module. Dimensionality reduction and change image generation were implemented with ENVI software by PCA functional module and manually designing band math separately. The gradient image is calculated by Sobel operator. The setting of parameters adopts the trial-and-error method and the segmentation results were evaluated visually until the segments are not too large and there is little over segmentation of the underlying objects. Eventually, the minimum suppression threshold was set to 0.015 , the size of the spatial filtering model of bilateral filtering was set to 9, and the local scale statistics window size is set to 15. All the experiment methods reported on this section have been applied to Yushu data set.

\subsection{PCs difference change detection based on segments (PCDCD)}

The method of PCDCD consists of two steps. The first step involves addressing the texture feature for watershed segmentation. The second step is to identify the difference image between the texture feature segments to detect information of earthquake damaged buildings. Although the suppression threshold is set, watershed segmentation often produces oversegmentation, which produces several small regions. To reduce the number of segmented regions, the results of the image processing should be combined after the segmentation. We solve these problems by setting the appropriate merging threshold in this experiment. Merging refers to the aggregation of adjacent segments with similar features into an object. Visual assessment method is adopted in this study to evaluate the effect. The evaluation criterion is that the broken points around the segment are merged into the segment without affecting other segments around it. After several tests, the appropriate merge threshold (which is set to 65) is selected. Then, a collection of small areas can represent a small group of buildings. Figure 8 presents the merged image. 


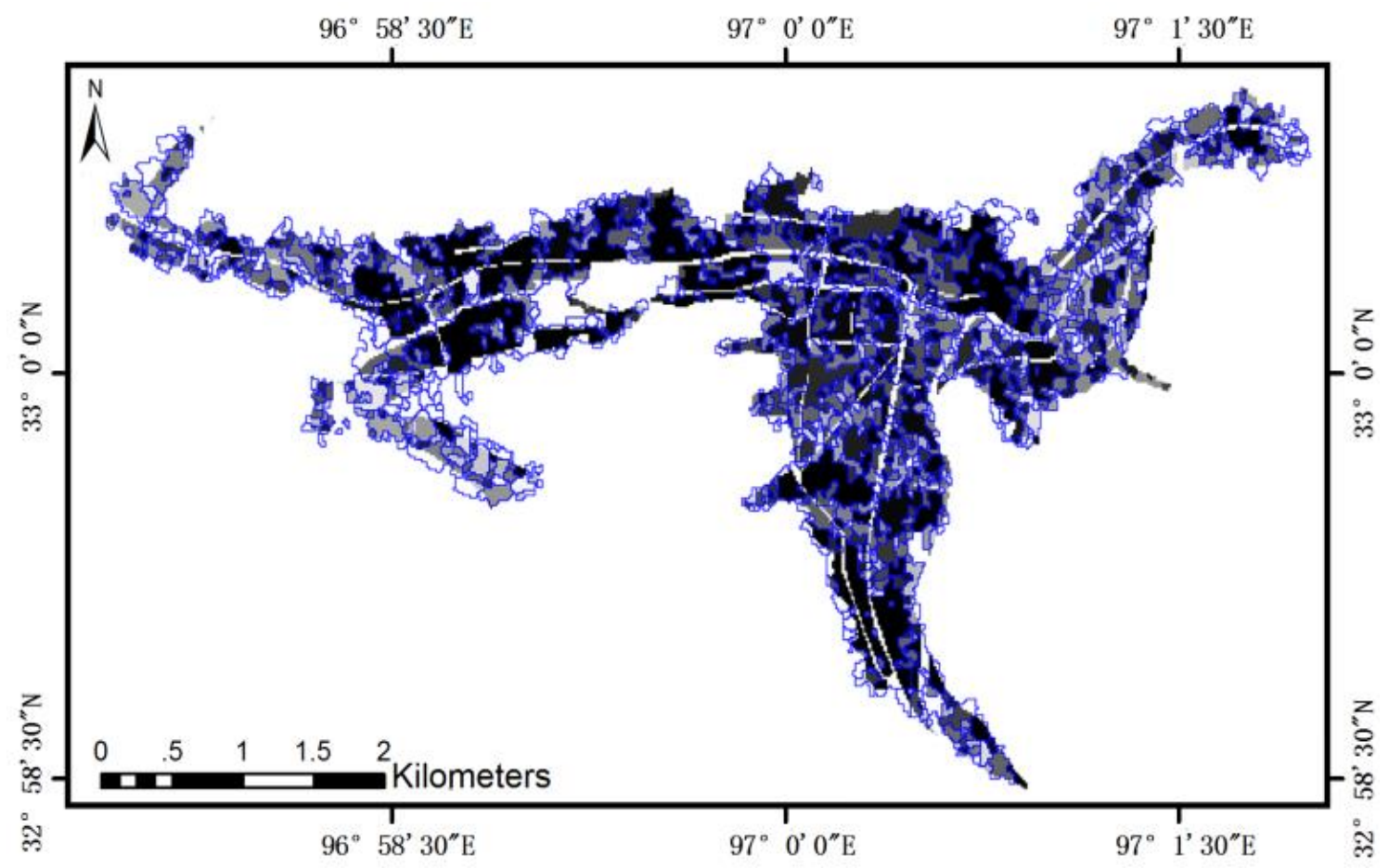

Figure 8: Split merge image, the merge parameters is 65 , each blue box

represents a segment

To obtain the optimal classification threshold, the sample point statistical analysis method is adopted. The sample point in the segment represents the value of the object. Each object takes the mean value of PC. The difference of 94 samples is used to obtain the threshold value of the change image (Table 3 ).

Table 3: Threshold distribution range of earthquake damage to buildings

\begin{tabular}{l|c|c|c}
\hline $\begin{array}{l}\text { Building damage } \\
\text { classification }\end{array}$ & $\begin{array}{c}\text { Intact } \\
\text { building }\end{array}$ & $\begin{array}{c}\text { Moderately } \\
\text { damaged building }\end{array}$ & $\begin{array}{c}\text { Destroyed } \\
\text { building }\end{array}$ \\
\hline Threshold & $0-34.8$ & $34.8-43.5$ & $43.5-201.2$ \\
\hline
\end{tabular}

The difference image is classified based on the statistical threshold. The distribution of building damage is shown in Figure 9. 


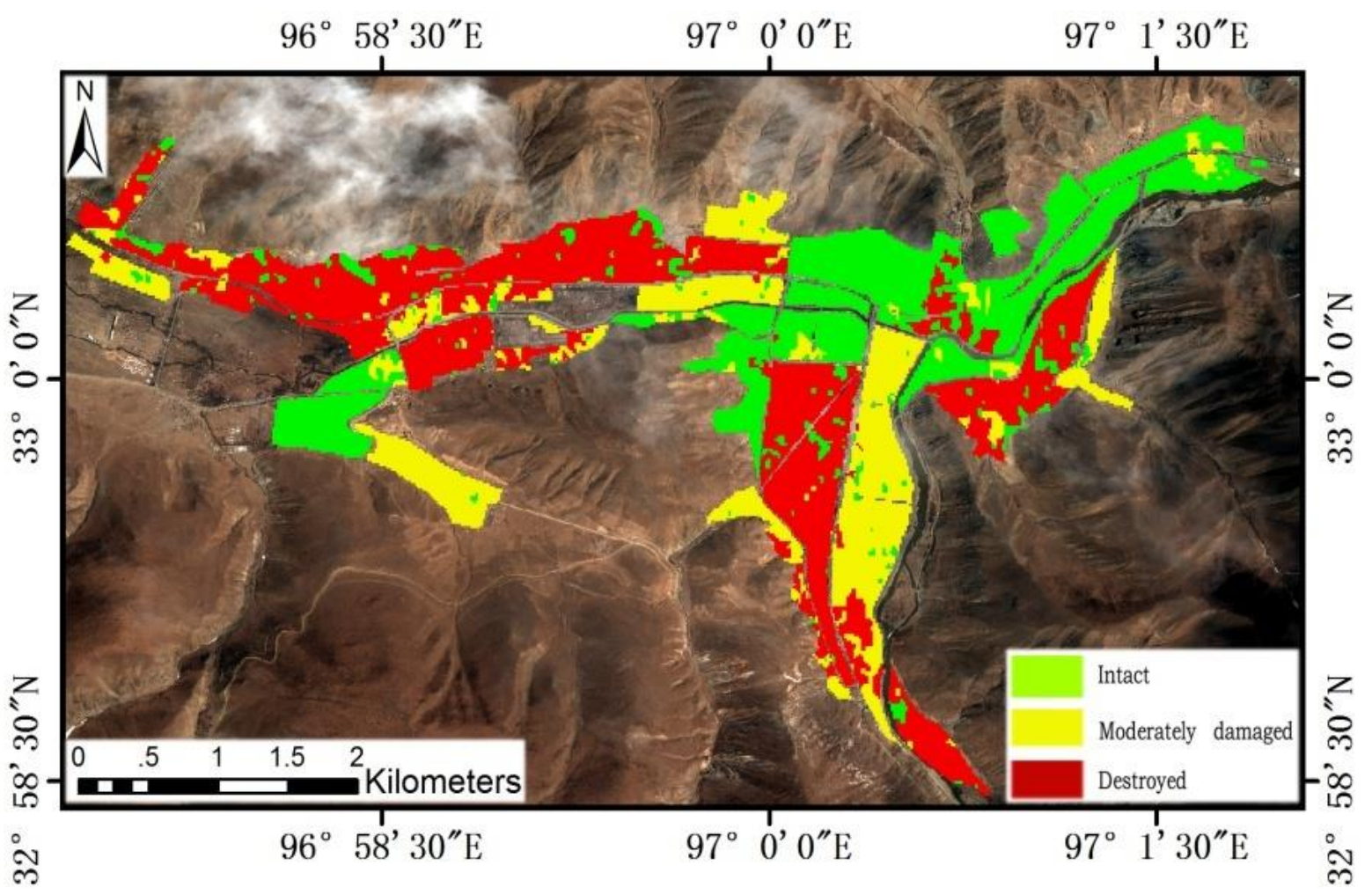

Figure 9: Results of earthquake damage to buildings based on PCDCD method.

The base map is an optical image from QuickBird.

\subsection{Texture difference change detection based on segments (TDCD)}

To further analysis the proposed methods, we achieved the difference change detection based on watershed segmentation of the ME, VA and HOM factors respectively. The algorithm of object generation is still watershed segmentation and the merge parameter is chosen 65 . The features of pre- and post-earthquake are used directly for the difference operation. The difference of 94 samples is used to obtain the threshold value of the difference image (Table 4).

Table 4: Threshold distribution range of earthquake damage to buildings. MEDCD means mean

difference change detection based on segments. HOMDCD means homogeneity difference change detection based on segments. VADCD means variance difference change detection based on watershed segments.

\begin{tabular}{c|c|c|c}
\hline Method & $\begin{array}{c}\text { Intact } \\
\text { building }\end{array}$ & $\begin{array}{c}\text { Moderately } \\
\text { damaged building }\end{array}$ & $\begin{array}{c}\text { Destroyed } \\
\text { building }\end{array}$ \\
\hline MEDCD & $0-18.2$ & $18.2-21.7$ & $21.7-68.3$ \\
\hline HOMDCD & $0-9.8$ & $9.8-30.5$ & $30.5-189.3$ \\
\hline VADCD & $0-2.6$ & $2.6-8.1$ & $8.1-20$ \\
\hline
\end{tabular}


The distribution of the earthquake damage obtained by the experimental comparison is shown in Figure 10. Figure 10(a) presents the result of MEDCD, Figure 10(b) presents the result of HOM DCD, and Figure 10 (c) presents the result of VADCD.
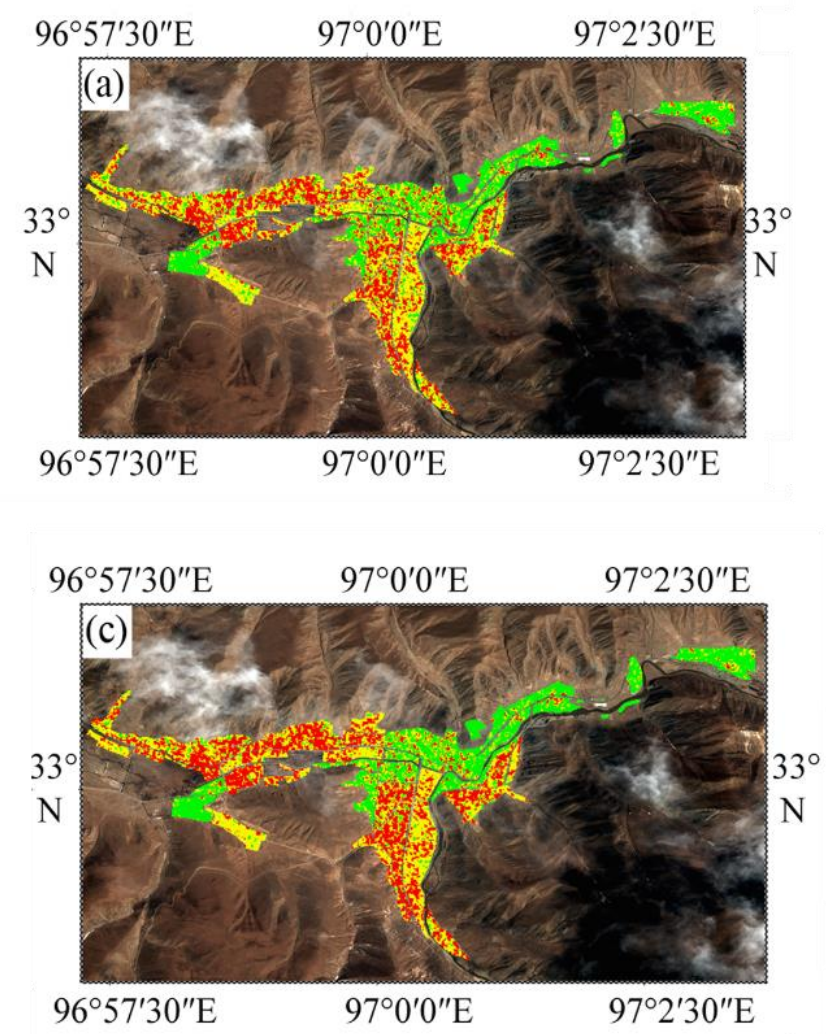

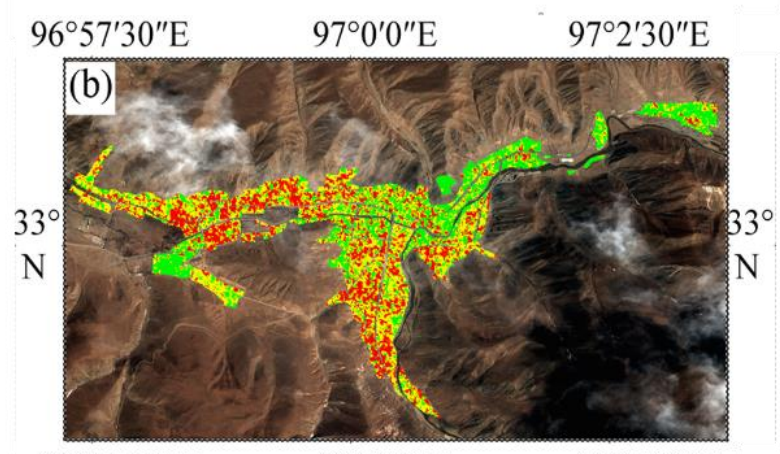

$96^{\circ} 57^{\prime} 30^{\prime \prime} \mathrm{E}$

$97^{\circ} 2^{\prime} 30^{\prime \prime} \mathrm{E}$

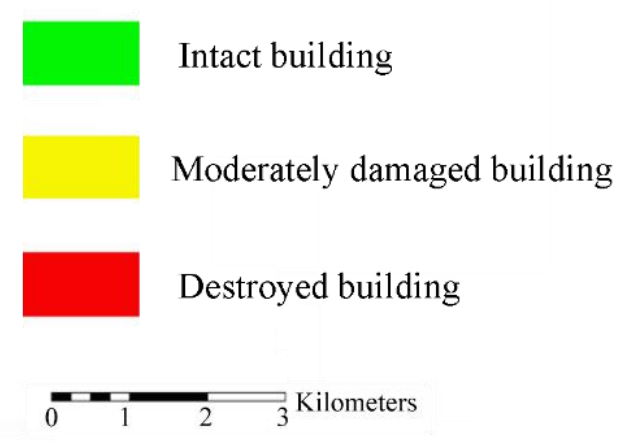

Figure 10: Distributions of assessed earthquake damage:((a) presents the results of difference change detection based on ME (MEDCD), (b) presents the results of difference change detection based on HOM (HOMDCD), and(c) presents the results of difference change detection based on VA (VADCD)).The method of change detection is the difference method, and the classification threshold is the sample statistical threshold (Table 4). The base map is an optical image from QuickBird.)

\subsection{Intensity difference change detection based on segments (IDCD)}

To verify the superiority of the proposed method compared with the gray features, we consider the original intensity image to detect the distribution of earthquake damaged building using the proposed method, in addition to the features involved in the gray features and no need for PCA. Images pre and post -earthquake are segmented by the watershed segmentation algorithm to generate segments. The difference method is used to calculate the difference images. The 94 samples are used to obtain the threshold value of the difference image (Table 5). The distribution of the seismic damage is shown in Figure 11. 
Table 5: Threshold distribution range of earthquake damage to buildings

\begin{tabular}{c|c|c|c}
\hline $\begin{array}{l}\text { Building damage } \\
\text { classification }\end{array}$ & $\begin{array}{c}\text { Intact } \\
\text { building }\end{array}$ & $\begin{array}{c}\text { Moderately damaged } \\
\text { building }\end{array}$ & $\begin{array}{c}\text { Destroyed } \\
\text { building }\end{array}$ \\
\hline Threshold & $0-33.2$ & $33.2-105.8$ & $105.8-254.9$ \\
\hline
\end{tabular}

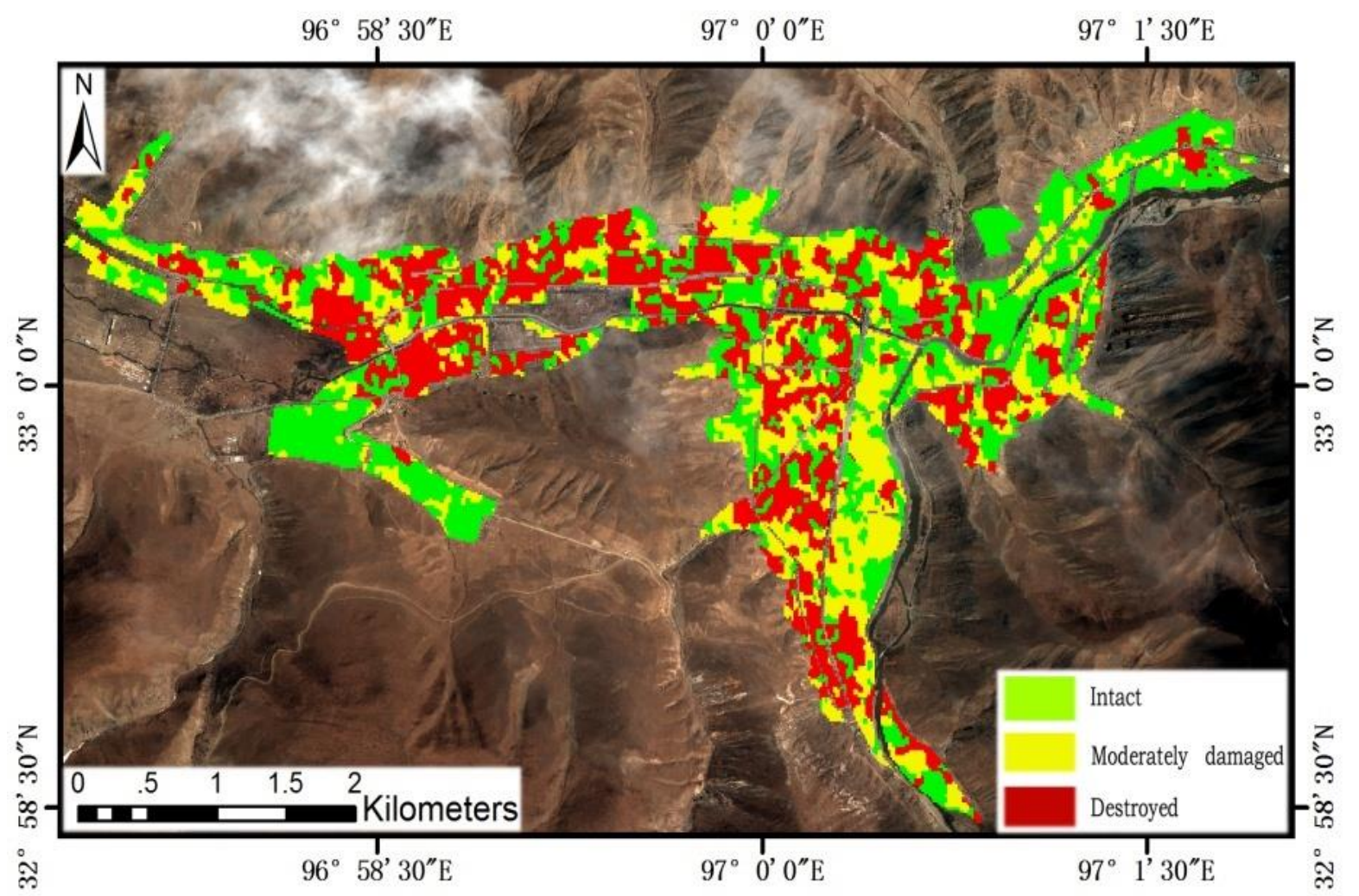

Figure 11: Distribution of assessed earthquake damage. The base map is an optical image from QuickBird.

\section{Discussion}

Four accuracy measures are selected to assess the results of the different experiments, including the extraction accuracy (EA), missed detection rate (MR), false detection rate (FDR) and the overall accuracy (OA). Its expressions are as follows:

$$
\begin{gathered}
E A=(T P-F P) / G T \\
M R=F N / G T \\
F D R=F P / T P
\end{gathered}
$$

Where TP means true positive area, FP means false positive area, GT means ground truth (If the results of the field investigation exist, the results should be considered. If not, the visual interpretation results of the optical image will be referred), and FN means false negative area. The OA expresses the overall accuracy of the three types of buildings with different grades of 
damage. Due to the lack of field survey data, we set the reference image referring to the existing earthquake damage assessment and visual interpretation of the QuickBird optical image (Figure 12) (Zhao, Yang and Li 2013; China Earthquake Administration; Guo et al. 2010).

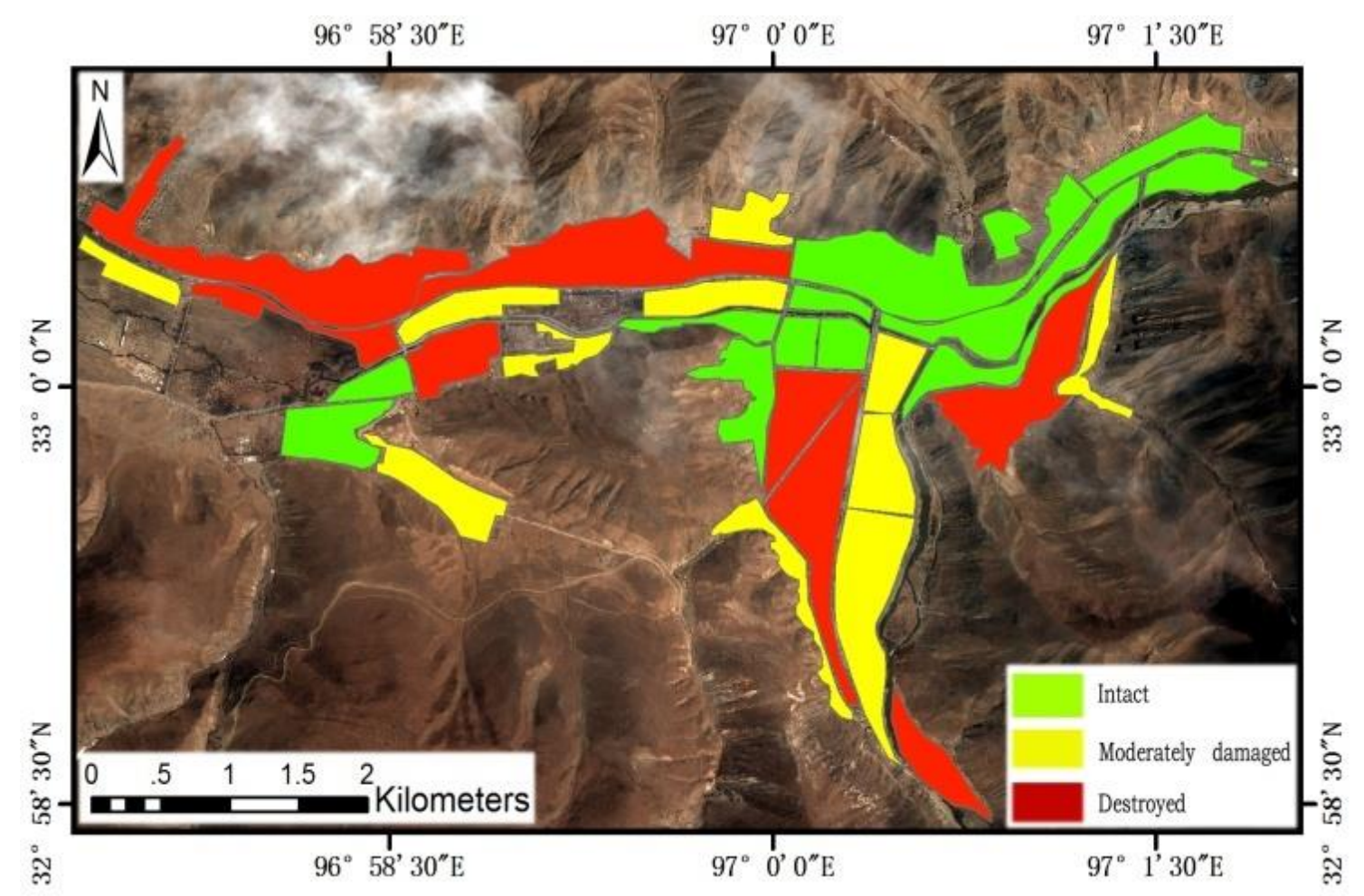

Figure 12: The reference image referring to the existing earthquake damage assessment and visual interpretation of the QuickBird optical image

\subsection{Analysis of the difference between pixel and segment}

Vulcanologia and Cnt (2009) described an automatic approach using different images to evaluate the infrastructure (roads, bridges) conditions. The processing methods include pixel-based and object-based methods. Lu et al. (2015) compared the new scheme with the traditional pixelbased change detection and the object-based change detection, the experimental results showed that object-based change detection was efficient. Techniques based on pixels consider the pixel as the basic unit in the process of describing a surface model. The factor that participates in the information extraction is the spectral information of the pixel (Oxoli and Brovelli 2018). The structure of the category and the correlation information between the adjacent pixels are rarely considered. Zhang and Gong (2013) proposed a feature change detection method based on object oriented method. But the feature used is only intensity. The spatial structure form of the segment is based on the difference in the attributes of the categories. Therefore, the characteristics of remote sensing image classification are not only reflected in terms of color but also in terms of shape, texture and other features. When the spectral features of the target are relatively similar, the texture features will play a positive role in the differentiation of the target (Tso and Mather 2001). Texture features are the best choice for earthquake damage target identification in SAR images with rich texture features. An image 
segmentation object based on texture features is a single, decomposed entity, in which pixel aggregates with similar texture information can be observed. Figure 9 shows that image segmentation can eliminate the influence of speckle noise and suppresses the generation of excessive speckle, which can reduce the rate of false detection. The results of CD based on object are compared with the results of change inferred from image pixels, and the comparison is shown in Table 6. It can be found that the buildings' EA values for the earthquake damage detection based on segment are higher than that based on the image pixel; the FDR is also lower than the method based on pixels. This shows that the generated segment is similar to the geographical entity. The pixels covered by the segment have the same characteristics, meaning that it is easier to detect the target, and the method can effectively improve the detection accuracy compared with the pixel-based method.

In the method of PCDCD, FDR of three types of earthquake damage building is $8.6 \%, 9.5 \%$, and $10.4 \%$ respectively. The reasons for these errors are that the segmentation is not uniform, and the procedure is affected by the presence of roads that are not covered by mask.

Table 6: Accuracy measures of the PCDCD and TDCD methods. (a) presents the measures of intact buildings, (b) presents the measures of moderately damaged buildings, and (c) presents the measures of destroyed buildings. For details on the accuracy measures (EA, MR, and FDR), see the text.

\begin{tabular}{l|c|c|c|c|c|c|c|c|c|c}
\hline \multirow{2}{*}{ Method } & \multicolumn{3}{|c|}{$\begin{array}{c}\text { Intact } \\
\text { building }\end{array}$} & \multicolumn{3}{c|}{ Moderately } & \multicolumn{3}{c|}{$\begin{array}{c}\text { Destroyed } \\
\text { damaged building }\end{array}$} & \multicolumn{3}{c}{ building } & OA \\
\cline { 2 - 10 } & EA & MR & FDR & EA & MR & FDR & EA & MR & FDR & $(\%)$ \\
& $(\%)$ & $(\%)$ & $(\%)$ & $(\%)$ & $(\%)$ & $(\%)$ & $(\%)$ & $(\%)$ & $(\%)$ & \\
\hline PCDCD & 88.9 & 11.1 & 8.6 & 89.1 & 10.9 & 9.5 & 84.3 & 15.7 & 10.4 & 89.3 \\
\hline TDCD & 75.6 & 24.4 & 15.7 & 78.3 & 21.7 & 18.2 & 73.9 & 26.1 & 14.4 & 72.7 \\
\hline
\end{tabular}

\subsection{Analysis of the differences between intensity and texture feature}

The general image CD method is mainly based on gray features. Many coherent speckles can be generated and influence the image quality, which produces many changes that are not present. The damage forms of buildings are complex and varied after earthquakes, and the gray level is usually very low in the SAR data. The destroyed building forms strong reflections from small dihedral angles, and reinforced and other building materials will make the gray level very high. Therefore, it is difficult to determine the distribution of damaged buildings by the change of the intensity. Texture features include the structure of the surface coverage and their relationship with the surrounding environment. The feature is more stable compared to the gray information, which will not be affected by the changes in the gray level of the target. The intact buildings are arranged in an orderly mode, while earthquakes destroy the texture features of orderly arrangements, thus, the differences in the texture features of the buildings before and after an earthquake can be clearly displayed. Wang et al. (2011) present a new texture feature change detection algorithm by comparing texture features of two times SAR images. Gong et al. (2014) proposed a novel change detection approach based on two difference images, which are constructed through intensity and texture information. The above research results prove the 
superiority of texture feature for change detection. However, not all texture features can distinguish different types of change we are interested in. The texture features selected need to reflect the characteristics of the building target as much as possible and make the differences between damaged buildings and intact buildings obvious. As shown in Table 7, the EA of buildings based on the selected texture features are significantly higher than that based on the gray level data, including intact building, moderately damaged building and destroyed building. Meanwhile, MR and FDR are also lower than those obtained based on intensity feature, which illustrates that texture features are more sensitive to damaged buildings in SAR images.

Table 7: Accuracy measures for the PCDCD and IDCD methods. (a) presents the measures of intact buildings, (b) presents the measures of moderately damaged buildings, and (c) presents the measures of destroyed buildings. For details on the accuracy measures (EA, MR, and FDR), see the text.

\begin{tabular}{l|c|c|c|c|c|c|c|c|c|c}
\hline \multirow{2}{*}{ Method } & \multicolumn{3}{|c|}{$\begin{array}{c}\text { Intact } \\
\text { building }\end{array}$} & \multicolumn{3}{c|}{$\begin{array}{c}\text { Moderately } \\
\text { damaged building }\end{array}$} & \multicolumn{3}{c|}{$\begin{array}{c}\text { Destroyed } \\
\text { building }\end{array}$} & OA \\
\cline { 2 - 10 } & $\begin{array}{c}\text { EA } \\
\text { (\%) }\end{array}$ & $\begin{array}{c}\text { MR } \\
(\%)\end{array}$ & $\begin{array}{c}\text { FDR } \\
(\%)\end{array}$ & $\begin{array}{c}\text { EA } \\
(\%)\end{array}$ & $\begin{array}{c}\text { MR } \\
(\%)\end{array}$ & $\begin{array}{c}\text { FDR } \\
(\%)\end{array}$ & $\begin{array}{c}\text { EA } \\
(\%)\end{array}$ & $\begin{array}{c}\text { MR } \\
(\%)\end{array}$ & $\begin{array}{c}\text { FDR } \\
(\%)\end{array}$ & $(\%)$ \\
\hline PCDCD & 88.9 & 11.1 & 8.6 & 89.1 & 10.9 & 9.5 & 84.3 & 15.7 & 10.4 & 89.3 \\
\hline IDCD & 70.4 & 29.6 & 18.3 & 72.6 & 27.4 & 20.1 & 68.7 & 31.3 & 23.9 & 67.4 \\
\hline
\end{tabular}

\subsection{Analysis of the difference between single texture feature and multi texture features}

Zhuang, Deng and Fan (2016) proposed an unsupervised change detection approach to highresolution SAR images based on texture feature vector and maximum entropy principle. The experimental results show that the proposed approach could both reduce the influence of speckle noise and improve the detection accuracy. Han et al. (2012) found difference images based on the contrast can stand out changed information better using texture features extraction of SAR images based on GLCM. They made the difference images based on the contrast as the base of change detection. Different texture features may reflect different information on the targeted building, thus, the different texture features often complement one another (Wen and Gao 2016). A single feature cannot fully reflect the characteristics of earthquake damaged buildings, but all the texture features will cause redundancy of information. In this experiment, we analyze the principle of the GLCM combination of multi texture features based on the segment. Table 8 presents the accuracy compared with the results from the PCA. We can find that the difference among EA values of the three single texture feature is large. The EA of VADCD is the highest, followed by HOMDCD, and MEDCD is the lowest. The EA of the first PC of the texture features is significantly higher than that of the single texture feature, which shows that the use of multiple features can reduce the FDR and improve the detection performance and accuracy. 
Table 8: Accuracy measures for the PCDCD, MEDCD, HOMDCD and VADCD methods; (a) presents the measures for intact buildings, (b) presents the measures for moderately damaged buildings, and (c) presents the measures for destroyed buildings. For details on the accuracy measures (EA, $M R, F D R)$, see the text.

\begin{tabular}{c|c|c|c|c|c|c|c|c|c|c}
\hline \multirow{2}{*}{ Method } & \multicolumn{3}{|c|}{$\begin{array}{c}\text { Intact } \\
\text { building }\end{array}$} & \multicolumn{3}{c|}{$\begin{array}{c}\text { Moderately } \\
\text { damaged building }\end{array}$} & \multicolumn{3}{c|}{$\begin{array}{c}\text { Destroyed } \\
\text { building }\end{array}$} & \multirow{2}{*}{ OA } \\
\cline { 2 - 11 } & $\begin{array}{r}\text { EA } \\
(\%)\end{array}$ & $\begin{array}{c}\text { MR } \\
(\%)\end{array}$ & $\begin{array}{c}\text { FDR } \\
(\%)\end{array}$ & $\begin{array}{c}\text { EA } \\
(\%)\end{array}$ & $\begin{array}{c}\text { MR } \\
(\%)\end{array}$ & $\begin{array}{r}\text { FDR } \\
(\%)\end{array}$ & $\begin{array}{c}\text { EA } \\
(\%)\end{array}$ & $\begin{array}{c}\text { MR } \\
(\%)\end{array}$ & $\begin{array}{c}\text { FDR } \\
(\%)\end{array}$ & $(\%)$ \\
\hline PCDCD & 88.9 & 11.1 & 8.6 & 89.1 & 10.9 & 9.5 & 84.3 & 15.7 & 10.4 & 89.3 \\
\hline MEDCD & 72.5 & 27.5 & 17.8 & 73.8 & 26.2 & 19.6 & 68.8 & 31.2 & 22.7 & 64.1 \\
\hline HOMDCD & 74.3 & 25.7 & 17.3 & 75.1 & 24.9 & 17.6 & 70.6 & 29.4 & 20.9 & 68.7 \\
\hline CVDCD & 75.0 & 25.0 & 15.8 & 77.3 & 22.7 & 16.2 & 72.4 & 27.6 & 17.7 & 71.2 \\
\hline
\end{tabular}

Remote sensing images from different data sources reflect different texture feature of earthquake damage. The texture features used in experiment are the first PC of three characteristic parameters ( $\mathrm{ME}, \mathrm{HOM}, \mathrm{VA})$, which is chosen to participate in the analysis and calculation taking image segment as a unit. The texture feature parameters of the different types of images and damage degrees may not be the same, in which case the extraction accuracy will be different.

\section{Conclusion}

In this paper, we present an object-level damage building detection method using texture features of pre- and post-earthquake SAR images based on watershed segmentation. The method used the watershed segmentation algorithm to segment the PCs of texture features after obtaining the optimal texture features. Then, samples were selected to calculate the classification threshold to obtain the distribution of the earthquake damaged buildings. Using ALOS-1 data related to the Yushu earthquake as an example, the proposed method had a higher accuracy compared with the direct difference change detection method. The method made innovations in the following ways. (1)The concept of object orientation was introduced to change detection, which represented an innovate from the conventional change detection methods that used the pixel as the unit.(2) The watershed segmentation algorithm was applied to texture features based on statistics, which made the segmentation more meaningful. The traditional change detection algorithm usually used pixels as the calculating unit, and the results often contained many broken spots. The innovation described in point 1 will have the same characteristics as the pixel set that formed the image segment, and the change detection method considered the object as a unit and avoided the generation of pixel spots. The watershed segmentation method was used to describe the image; and the gray value of the image pixel corresponded to the height of the topographic map; thus, the idea of the 
segmentation method was consistent with the statistical texture feature calculation method. This concept is also an innovation in point 2 of this paper, which made the segment of the texture feature more in line with the actual object, and improved the detection accuracy.

We demonstrated the effectiveness of the proposed approach using ALOS PALSAR data from Jiegu town, China, which was heavily damaged in the Yushu earthquake in April 2010. The result showed that the method was able to distinguish different grade damage buildings, with high overall accuracies of approximately $90 \%$. At the same time, we analyzed the differences between the results of $C D$ methods based on image segments and pixels, CD methods based on intensity and texture features, $C D$ methods based on single and multiple texture features. It is discovered that CD methods based on segment can achieve a better accuracy than those based on image pixels; $C D$ methods based on texture features can achieve a better accuracy than those based on intensity feature; and CD methods based on multiple texture features can achieve a better accuracy than those based on single texture feature. In summary, the multi texture features combination segmentation method can effectively detect damaged buildings by suppressing the effects of speckle noise and other influencing factors, thereby improve the accuracy of detection. In future work, more features should be acquired especially polarization features to further improve the detection accuracy.

\section{Acknowledgement}

The authors wish to thank the anonymous reviewers for their comments. This work was supported by the Special Item for Public Welfare of Scientific Research Project from Institute of Crustal Dynamics, China Earthquake Administration (ZDJ-2017-29), the National Natural Science Foundation of China (Grant No. 41374050) and Civil Aerospace Project (D010102).

\section{References}

Abdi, H. and Williams, L. J. 2010.Principal Component Analysis. Wiley Interdisciplinary Reviews Computational Statistics, 2(4), pp.433-459.

Aghababaee, H. Amini, J. and Tzeng, Y. C. 2013. Improving change detection methods of SAR image using fractals. Science Iranica, 20(1), pp. 15-22.

Aghababaee, H. Tzeng, Y C. and Amini, J. 2012. Swarm intelligence and fractals in dual-pol synthetic aperture radar image change deception. Journal of Applied Remote Sensing, 6(1), pp.63586-63596.

Aoki, H. Matsuoka, M. and Yamazaki, F. 1998. Characteristics of satellite SAR images in the damaged areas due to the Hyogoken-Nanbu earthquake. Proc. 19th Asian Conference of Remote Sensing. C7, pp.1-6.

Balz, T. and Liao, M.S. 2010. Building-damage detection using post-seismic high-resolution SAR satellite data. International Journal of Remote Sensing, 31(13), pp.3369-3391. 
Berberoglu, S. Curran, P. J. and Lloyd, C. D., et al.2007. Texture classification of Mediterranean land cover. International Journal of Applied Earth Observation and Geo-information, 9(3), pp.322334.

Blaschke, T. 2010. Object based image analysis for remote sensing. ISPRS Journal of Photogrammetry and Remote Sensing, 65 (1), pp.2-16.

Blaschke, T. Lang, S. and Hay, G. 2008. Object-based image analysis: spatial concepts for knowledge-driven remote sensing applications. Berlin/Heidelberg, Germany: Springer Science \& Business Media.

Bouziani, M. Goïta, K. and He D. C. 2010. Automatic change detection of buildings in urban environment from very high spatial resolution images using existing geodatabase and prior knowledge. ISPRS Journal of Photogrammetry and Remote Sensing, 65 (1), pp.143-153.

Chen, G. Geoffrey, J. and H. Luis, M., et al. 2012. Object-based change detection. International Journal of Remote Sensing, 33 (14), pp.4434-4457.

Chen, Z. P. and Deng, P. 2002.Application of textural features to change detection in SAR image. Remote Sensing Technology and Application, 17(3), pp. 162-166.

China Earthquake Administration. Preliminary results of remote sensing investigation of Yushu earthquake in Qinghai. http://www.cea.gov.cn/manage/html.

China Earthquake Administration. 2008. GB/T 17742-2008 Chinese seismic intensity scale. Beijing: Standards Press of China.

Chini, M. 2009. Earthquake damage mapping techniques using SAR and Optical remote sensing satellite data. In Advances in Geoscience and Remote Sensing. Italia: IntechOpen, pp. 269-278.

Coppin, P. and Bauer, M. 1994. Processing of multitemporal Landsat TM imagery to optimize extraction of forest cover change features. IEEE Transaction on Geoscience and Remote Sensing, 32(4), pp.918-927.

Domenikiotis, C. Loukas, A. and Dalezios, N. R. 2003. The use of NOAA/AVHRR satellite data for monitoring and assessment of forest fires and floods. Natural Hazards and Earth System Science, $3(1 / 2)$, pp.115-128.

Fan, H. S., Ma, A. N. and Li,J. 2001.Case study on image differencing method for land use change detection using thematic data in Renhe district of Panzhihua. Journal of Remote Sensing, 5(1), pp.75-80.

Feng, T., Hong, Z. and Ma, S., et al. 2014. Application and prospect of a high-resolution remote sensing and geo-information system in estimating earthquake casualties. Natural Hazards and Earth System Science, 14 (8), pp. 2165-2178.

Ferro, C. J. 2002.Seale and texture in digital image classification. Photogrammetric Engineering and Remote Sensing, 68(I), pp.51-63.

Gamba, P., Dell'Acqua, F. and Trianni, G. 2007. Rapid damage detection in the Bam area using multitemporal SAR and exploiting ancillary data. IEEE Transactions on Geoscience and Remote Sensing, 45(6), pp.1582-1589.

Gao, C.S., Zhang, H. and Wang, C. 2010. SAR change detection based on generalized gamma distribution divergence and auto-threshold segmentation. Journal of Remote Sensing, 14 (4), pp.710-724. 
Gong, M., Li, Y. and Jiao, L, et al. 2014. SAR change detection based on intensity and texture changes. ISPRS Journal of Photogrammetry and Remote Sensing, 93(93), pp.123-135.

Gong, M. G., Yang, H. L. and Zhang, P. Z. 2017. Feature learning and change feature classification based on deep learning for ternary change detection in SAR images. Journal of Photogrammertry and Remote Sensing, (129), pp.212-225.

Gonzalez, R. C. and Woods, R. E. 2005. Digital Image Processing (Second Edition). Publishing House of Electronics Industry.

Guo, H. D., Zhang, B. and Lei, L P., et al. 2010. Spatial distribution and inducement of collapsed buildings in Yushu earthquake based on remote sensing analysis. Science China Earth Science, 53(6), pp.794-796.

Hachicha, S. and Chaabane, F. 2014. On the SAR change detection review and optimal decision. International Journal of Remote Sensing, (5), pp.1693-1714.

Han, C. M., Guo, H D. and Wang, C. L. 2002.The essence of SAR image speckle suppression. Journal of Remote Sensing, 6(6), pp.470-474.

Han, J., Deng K. and CUMT, -, et al. 2012. SAR image change detection methods based on GLCM texture features. Journal of Geodesy \& Geodynamics, 32(4), pp.94-98.

Hao, H. M., Zhang, Y H. and Shi, H Y. 2012.Application of test statistic method in fully polarimetric SAR change detection. Journal of Remote Sensing, 16(3), pp.520-532.

Haralick, R.M., Shanmugan, K. and Dinstein, I. 1973.Texture features for image classification. IEEE Transactions on System, Man and Cybernetics, 3, pp.610-621.

HEROLD, N. D. H., AACK, B. N. and SOLOMON, E. 2004. An evaluation of Radar texture for land use/cover extraction in varied landscapes. International Journal of Applied Earth Observation and Geo-information, 5(2), pp.113-128.

Hosonuma, N. M., Herold, V. and De Fries, R. S, et al. 2012. An assessment of deforestation and forest degradation drivers in developing countries. Environmental Research Letters, 7 (4), pp.044009.

Hou, B., Wei, Q. and Zheng, Y., et al. 2017. Unsupervised change detection in sar image based on gauss-log ratio image fusion and compressed projection. IEEE Journal of Selected Topics in Applied Earth Observations \& Remote Sensing, 7(8), pp.3297-3317.

Huang, S Q., Liu, D. Z. and Hu, M. X., et al. 2010.Multi-temporal SAR image change detection technique based on wavelet transform. Acta Geodaetica et Cartographical Sinica, 39(2), pp.180186.

Hussain, M., Chen, D. and Cheng, A., et al. 2013. Change detection from remotely sensed images: from pixel-based to object-based approaches. ISPRS Journal of Photogrammetry and Remote Sensing, 80, pp.91-106.

Hu, Z. L. 2013. An unsupervised change deception approach based on KI Dual Thresholds under the Generalized Gauss Model Assumption in SAR images. Acta Geodaetica et Cartographical Sinica, (1), pp.116-122.

Hu, Z L., Li, H. Q. and Du, P J. 2009.Study on the extraction of texture features and its application in classifying SAR images. Journal of China University of Mining \& Technology, 38(3), pp.422-427. 
Ito, Y., and Hosokawa, M. 2002. Damage estimation model using temporal coherence ratio. IGARSS, (5), pp.2859-2861.

Ito, Y., Hosokawa, M. and Matsuoka, M. 2003. A degree estimation model of earthquake damage using temporal coherence ratio. IGARSS, (5), pp.2410-2412.

Jin, Y. Q., and Wang, D. F. 2009.Automatic detection of terrain surface changes after wenchuan earthquake, May 2008, from ALOS SAR images using 2EM-MRF method. IEEE Transactions on Geoscience and Remote Sensing, 6(2), pp.344-348.

Jolliffe, I. T. 1986. Principal Component Analysis. Springer, Berlin, 87(100), pp. 41-64.

Kaiser, G., Burkhard, B. and Römer, H., et al. 2013. Mapping tsunami impacts on land cover and related ecosystem service supply in Phang Nga, Thailand. Natural Hazards and Earth System Science, 13 (12), pp.3095-3111.

Kamthonkiat, D., Rodfai, C. and Saiwanrungkul, A, et al. 2011. Geoinformatics in mangrove monitoring: damage and recovery after the 2004 Indian Ocean Tsunami in Phang Nga, Thailand. Natural Hazards and Earth System Science, 11 (7), pp.1851-1862.

Lahousse, T., Chang, K. T. and Lin, Y. H. 2011. Landslide Mapping with multi-scale object-based image analysis - a case study in the baichi watershed, Taiwan. Natural Hazards and Earth System Science, 11 (10), pp.2715-2726.

Li, J. W., Bo, J. S., Lu, T., et al. 2013.Seismic damage analysis of school buildings in Yushu Ms 7.1 earthquake. Journal of Nature Disasters, 22(1), pp.123-129.

Liu, H., and Guo., H. D. 1995. The extraction of texture information from Radar image and its value in geo-science analysis. Remote Sensing of Environment, 10(2), pp.107-114.

Lu, J., Li, J. and Chen. G., et al.2015. Improving Pixel-Based change detection accuracy using an object-based approach in multitemporal SAR flood images. IEEE Journal of Selected Topics in Applied Earth Observations \& Remote Sensing, 8(7), pp.3486-3496.

Marino, A. and Hajnsek, I.A .2014.A change detector based on an optimization with polarimetric SAR imagery. IEEE Transaction on Geoscience and Remote Sensing, 52(8), pp.4781-4798.

Matsuoka, M. and Nojima,N.2010a.Building damage estimation by integration of seismic intensity information and satellite L-band SAR imagery. International Journal of Remote Sensing, 2(9), pp.2111-2126.

Matsuoka, M. and Yamazaki, F. 2000.Use of interferometric satellite SAR for earthquake damage detection. Proc. of 6th International Conference on Seismic Zonation, EERI.

Matsuoka, M. and Yamazaki, F. 2004a. Use of satellite SAR intensity imagery for detecting building areas damaged due to earthquakes. Earthquake Spectra, 20(3), pp. 975-994.

Matsuoka, M. and Yamazaki, F. 2004b .Building damage detection using satellite SAR intensity images for the 2003 Algeria and Iran earthquakes. IGARSS, (2), pp.1099-1102.

Matsuoka, M. and Yamazaki, F.2005. Building damage mapping of the 2003 Bam, Iran, earthquake using Envisat/ASAR intensity imagery. Earthquake Spectra, 21(S1), pp.285-294.

Matsuoka, M., Yamazaki, F. and Ohkura, H. 2007.Damage mapping for the 2004 Niigata-ken Chuetsu earthquake using Radarsat images. Urban Remote Sensing Joint Event, pp.1-5. 
Matsuoka, M., Koshimura, S. and Nojima, N. 2010.Estimation of building damage ratio due to earthquakes and tsunamis using satellite SAR imagery. IGARSS. pp.3347-3349.

Miller, L. D.. Nualchawee, K. and Tom, C. 1978. Analysis of dynamics of shifting cultivation in the Otropic forest of northern Thailand using landscape modeling and classification of Landsat imagery. Technical Memorandum. Grenbelt, MD.

Moya, L. Mas, E. and Adriano, B, et al. 2017.Building damage mapping using change detection of ALOS-2 PALSARr-2 SAR images and strong motion data. International Symposium on Remote Sensing. Nagoya, Japan.

Nunes, C. and Auge, J. I. 1999. Land-use and land-cover change (LUCC): implementation strategy. Environmental Policy Collection. Stockholm, Sweden: IGBP Secretariat.

Oxoli, D., Boccardo, P. and Brovelli, M.A. 2018. Coherent change detection for repeated-pass interferometric SAR images: an application to earthquake damage assessment on buildings. The International Archives of the Photogrammetry, Remote Sensing and Spatial Information Sciences, Volume XLII-3/W4, 2018 Geolnformation For Disaster Management (Gi4DM), March 2018, Istanbul, Turkey, pp.18-21.

Roemer, H., Kaiser, G. and Sterr, H., et al. 2010. Using remote sensing to assess tsunami-induced impacts on coastal forest ecosystems at the Andaman sea coast of Thailand. Natural Hazards and Earth System Sciences, 10 (4), pp. 729-745.

Römer, H., Willroth, P. and Kaiser, G., et al. 2012.Potential of remote sensing techniques for tsunami hazard and vulnerability analysis - a case study from Phang-Nga Province, Thailand. Natural Hazards and Earth System Science, 12(6), pp.2103-2126.

Serpico, S. B. and Moser, G. 2007. Unsupervised change detection from multichannel SAR data by markov random fields. IEEE Geoscience \& Remote Sensing Letters, 4(2), pp.363-388.

Shalaby, A. and Tateishi, R. 2007. Remote Sensing and GIS for mapping and monitoring land cover and land-use changes in the Northwestern coastal zone of Egypt. Applied Geography, 27(1), pp.28-41.

Sharma, R., Tateishi, R. and Hara, K, et al. 2017. Earthquake Damage Visualization (EDV) technique for the rapid detection of earthquake-induced damages using SAR data. Sensors, 17, pp.235.

Tanathong, S., Rudahl, K. T. and Goldin, S. E. 2009. Object oriented change detection of buildings after a disaster. In Proceedings of the American Society for Photogrammetry and Remote Sensing Annual Conference 2009 (ASPRS 2009), pp.9-13.

Tso, B. and Mather, P. M.2001. Classification methods for remotely sensed data. Taylor and Francis Inc.

Tuceryan, M. and jain, A. K. 1998. Texture analysis, the handbook of pattern recognition and computer vision. World Scientific Publishing. pp. 207-248.

Vincent, L. and Soille, P. 1991.Watersheds in digital spaces: an efficient algorithm based on immersion simulations. IEEE Transactions on Pattern Analysis and Machine Intelligence, 13(6), pp.583-598.

Wal, D.V.D., Herman, P.M.J. and Dool, W.V.D. 2005. Characterisation of surface roughness and sediment texture of intertidal flats using ERS SAR imagery. Remote Sensing of Environment, 98(1), pp.96-109. 
Walter, V. 2004. Object-based classification of remote sensing data for change detection. ISPRS Journal of Photogrammetry and Remote Sensing, 58 (3), pp. 225-238.

Wang, G. X., Huang, X. T. and Zhou, Z. M., et al. 2011. A new SAR image change detection algorithm based on texture feature. Proceeding of the 3rd International Asia-Pacific Conference on Synthetic Aperture Rader. Seoul, Korea.

Wen, C. and Gao, Z. 2011. Change detection in high resolution SAR images based on multiscale texture features. Proceedings of SPIE - The International Society for Optical Engineering, 8006(1), pp.84.

Wu, F., Wang, C. and Zhang, H.2005. Residential areas extraction in high resolution SAR image based on texture features. Remote Sensing Technology and Application, 20(2), pp.148-153.

Wulder, M. A., White, J. C. and Coops, N. C, et al. 2008. Multi-Temporal Analysis of High Spatial Resolution Imagery for Disturbance Monitoring. Remote Sensing of Environment, 112 (6), pp. 2729-2740.

Xie, H S., Zhang, H. and Xu, X. 2007.Classification method of texture images using the support vector machines and dual-tree complex wavelet transform. Journal of China University of Mining \& Technology, 36(6), pp.773-778.

Xiong, B. L. Chen, J. M. and Kuang, G. Y. 2012.A change detection measure based on a likelihood ratio and statistical properties of SAR intensity images. Remote Sensing Letters, 3(3), pp.267-275.

Yakoub, B., Lorenzo, B. and Farid, M. 2005. An unsupervised approach based on the generalized Gaussian model to automatic change detection in multi-temporal SAR images. IEEE Transactions on Geo-science and Remote Sensing, 43(4), pp. 874-887.

Yamazaki, F., Inoue, H. and Liu, W. 2010. Characterization of affected areas of the 2008 IwateMiyagi, Japan, earthquake using SAR intensity images. IGARSS, pp. 4660-4663.

Yonezawa, C. and Takeuchi, S. 1999.Detection of urban damage using interferometric SAR decorrelation. IGARSS 1999, (2), pp.925-927.

Yonezawa, C. and Takeuchi, S. 2001.Decorrelation of SAR data by urban damages caused by the 1995 Hyogoken-nanbu earthquake. International Journal of Remote Sensing, 22(8), pp.15851600.

Yonezawa, C. Tomiyama, N. and Takeuchi, S. 2002.Urban damage detection using decorrelation of SAR interferometric data. IGARSS, (4), pp.2051-2053.

Yu, S. Z. 2010. Investigation and analysis of earthquake damage to the residential buildings in Yushu M. 7.1 earthquake. Journal of Civil, Architectural \&Environmental Engineering, (32), pp.1315.

Zhang, J. and Gong, L. 2013. SAR images before and after earthquake change detection based on object-oriented method and damage evaluation. Geoscience and Remote Sensing Symposium, pp.692-694.

Zhang, J., She, Q. and Pan, L. 2008.Change detection of residential area by remote sensing image based on LBP/C texture. Geomantic and Information Science of Wuhan University, 33(1), pp.7-11.

Zhao, L J., Qin, Y L. and Gao, G. 2008. Detection of built-up areas from high resolution SAR images using the GLCM textural analysis. Journal of Remote Sensing, 13(3), pp.483-490. 
Zhao, L., Yang, J. and Li, P., et al. 2013. Damage assessment in urban areas using post-earthquake airborne Polar imagery. International Journal of Remote Sensing, 34(24), pp.8952-8966.

Zhao, Y. D. Zhang, L. P. and Li, P. X. 2006. Universal markov random fields and its application in multispectral textured image classification. Journal of Remote Sensing, 10(1), pp.123-129.

Zhuang, H., Deng, K. and Fan, H. 2016. SAR images unsupervised change detection based on combination of texture feature vector with maximum entropy principle. Acta Geodaetica Et Cartographica Sinica, 45(3), pp.339-346. 